\title{
Chronoamperometric Cu(II) Analysis at Gold Ultramicroelectrodes in Concentrated Sulfuric Acid Solutions
}

\author{
H. Gómez, ${ }^{1, *}$, G. Riveros ${ }^{2}$, D. Ramírez ${ }^{2}$ \\ ${ }^{1}$ Instituto de Química, Pontificia Universidad Católica de Valparaíso, Avda. Universidad 330, \\ Curauma, Valparaíso, Chile. \\ ${ }^{2}$ Instituto de Química y Bioquímica, Facultad de Ciencias, Universidad de Valparaíso, Avda. Gran \\ Bretaña 1111, Playa Ancha, Valparaíso, Chile. \\ *Email: humberto.gomez@ pucv.cl
}

doi: $10.20964 / 2017.02 .09$

Received: 30 September 2016 / Accepted: 25 November 2016 / Published: 30 December 2016

\begin{abstract}
Chronoamperometric analysis of $\mathrm{Cu}$ (II) ion concentration at a gold ultramicroelectrode (UME) is reported. An appropriate potential/time program was selected after the analysis of the corresponding $\mathrm{j}$ $v s \mathrm{t}$ transients in order to establish a defined value in the limiting current for analytical purposes. Good linearity between $\mathrm{Cu}$ (II) concentration and the stationary stripping current was obtained in the concentration of $5 \mathrm{~g} \mathrm{dm}^{-3}$ to $150 \mathrm{~g} \mathrm{dm}^{-3}$ range. Moreover, interference effects from sulfuric acid in a wide concentration range and from additives such as thiourea and glue showed that they do not affect the linearity between the stationary current values and $\mathrm{Cu}$ (II) concentration. These results could be adapted for the chronoamperometric detection of $\mathrm{Cu}$ (II) in on-line measurements in industrial copper refining electrolytes.
\end{abstract}

Keywords: copper analysis, chronoamperometry, ultramicroelectrodes, industrial electrorefining electrolytes.

\section{$\underline{\text { FULL TEXT }}$}

(C) 2017 The Authors. Published by ESG (www.electrochemsci.org). This article is an open access article distributed under the terms and conditions of the Creative Commons Attribution license (http://creativecommons.org/licenses/by/4.0/). 